This report was prepared as an account of work sponsored by an agency of the United States Government. Neither the United States Government nor any agency thereof, nor any of their employees, makes any warranty, express or implied, or assumes any legal liability or responsibility for the accuracy, compteteress, or usefulness of any injormation, apparatus. product, or process disclosed, or represents that its use would not infringe privately owned rights. Reference herein to any specific commercial pruduct, process, or service by trade name, trademark. manufacturer, or otherwise does not necessarily constitute or impiy its endorsement, recommendation, or favoring by the United States Government or any agency thereof. The views and opinions of authors expressed herein do nol necessarily stale or reffect those of the United States Government or any agency thereof.

LBL -27553

DE90 001541

\title{
Multiple Electron Capture in Close Ion-Atom Collisions
}

\author{
A.S. Schlachter, , J.W. Stearns, a K.H. Berkner, E.M. Bernstein,b M.W. Clark,b \\ R.D. DuBois, C W.G. Graham,d T.J. Morgan,e D.W. Mueller, M.P. Stockli,b J.A. Tanis,b \\ and W.T. Woodlandb \\ a) Lawrence Berkeley Laboratory, Berkeley, California USA \\ b) Western Michigan University, Kalamazoo, Michigan USA \\ c) Pacific Northwest Laboratory, Richland, Washington USA \\ d) Queen's University, Belfast, Northern Ireland \\ e) Wesleyan University, Middletown, Connecticut USA \\ f) University of North Texas, Denton, Texas USA \\ g) Kansas State University, Manhattan, Kansas USA
}

\author{
Accelerator and Fusion Research Division \\ Lawrence Berkeley Laboratory \\ 1 Cyclotron Road \\ Berkeley, California 94720
}

July 24, 1969

Paper presented at the Sixteenth Intermational Conference on the Physics of Electron and Atomic Collinione, New York, 26 July - 1 Auguet, 1909

This work wes supperted by the Disector, Otfice of Energ Reaench, Office of Davic Energy Sciences,

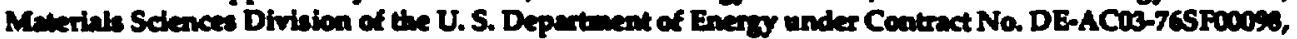
the U.S. Departent of Enery, Office of Baic Enery Sciences, Divition of Chemical Sciences, the Office of Health and Environmental Research under Contract DE-ACO6-76RL01830, the Western Michigan University Faculty Research and Creative Activities Support Fund, and the UKSERC.

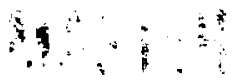


MULTIPLE ELECTRON CAPTURE IN CLOSE ION-ATOM COLLISIONS

\author{
A.S. Schlachter, J.W. Steams, ${ }^{a}$ K. H. Berkner, a E. M. Bernstein, b \\ M.W. Clark,b R.D. DuBois, , W.G. Graham, d T.J. Morgan,e \\ D.W. Mueller, M.P. Stockli,g J.A. Tanis, b and W. T. Woodlandb
}
a) Lawrence Berkeley Laboratory, Berkeley, California USA
b) Western Michigan University, Kalamaz0o, Michigan USA
c) Pacific Northwest Laboratory, Richland, Washington USA
d) Queen's University, Belfast, Northem Ireland
e) Wesleyan University, Middktown, Connecticut USA
f) University of North Texas, Denton, Texas USA
B) Kansas State University, Manhattan, Kansas USA

\begin{abstract}
Collisions in which a fast highly charged ion passes within the orbit of $\mathrm{K}$ electrons of a target gas atom are selected by emiscion of a K x-ray from the projectile or target. Measurement of the projectile charge state after the collision, in coincidence with the $K$ $x$-ray, allows measurement of the charge-transfer probability during these close collisions. When the projectile velocity is approximately the same as that of target electrons, a large number of electrons can be transferred to the projectile in a single collision. The electron-capture probability is found to be a linear function of the number of vacancies in the projectile $L$ shell for $47-\mathrm{MeV}$ calcium ions in an $A r$ target.
\end{abstract}

\section{NTRODUCTION}

Charge transfer in ion-atom collisions is a fundamental process of considerable interest. The probability of capturing an electron in a collision is a function of the impact parameter for the collision, as vell as a function of projectile velocity and charge state. Collisions in which a fast ion projectile paseses close to a target atom, e.g., within the $K$ or $L$ shell, can be selected by measuring the angle through which the projectile is scattered in the collision: the projectile is scattered through a langer angle in a close collision than in a more distant one. $1-5$ A lesa direct method of selecting close collisions is coincident detection of highly charged target recoil ions: a highly charged recoil ion implies that a close collision has taken plece.6.9 The impact-parameter dependence of inner-shell vacancy production hes also been studied by mewring coincidences between charge transfer and $x$-ray emiacion. 10

We have measured 11 cross sections for electron capture in coincidence with Ca or Ar $\mathrm{K} \times$-ray emiscion for $47-M e V C_{1}{ }^{7}++A r$, and showed that the crow section for capturing several electrons in a cluse coltision can exceed that for capturing only one electron. The only previous report of the cross section for multiple-electron capture being larger than that for single-electron copture, determined by ion-x-ray coincidence, is the observation of double K-10-K transfer in collisions of bare $45-\mathrm{MeV} / \mathrm{u}$ Si ions in Ar. 12 The results of reference 11 were recently extended to measure copture of up to eight electrons, and the projectile velocity has been varied. $13 \mathrm{New}$ results are presented here for varying the projectile charge state, which varies the number of initial vacancies in the projectile $L$ shell.

\section{APPARATUS AND METHOD}

The apparatus and methods employed are similar 11,13,14 to those previously used. The apparatus is shown schematically in Fig. 1. A beam of fas $C a$ ions from the LBL SuperHILAC accelerator was pased through a thin foil, and ions in a given charge state were selected by a magnet. Calcium ions 
in charge states from $17+$ (lithium-like) to $10+$ (neonlike) were collimaied and tiven passed through a differentially pumped gas cell. The magneticallyanalyzed $\mathrm{Ca}$ ions were measured after the collision using a Faraday cup and electrometer for those ions which did not change charge in the target, while ions which captured one to eight electrons were counted with solid-state detectors. A si(Li) x-ray detector viewed the gas cell. Coincidences between $x$ rays and projectiles which captured electrons were measured by starting time-to-digital or time-toamplitude converters (TDCs or TACs) with an $x$-ray signal, and stopping them wilh delayed signals from the particle detectors. The data were corrected for absorption of $x$-rays in the detector window and for the detector solid angle. Errors were minimizad by using a very thin target relative to all relevant electron-capture and -lows cross sections and by correcting for background effects. The relative uncertainties in the cross sections reported here are $\pm 25 \%$, the systematic uncertainty is $\pm 30 \%$, for an absolute uncertainty of approximately $\pm 10 \%$.

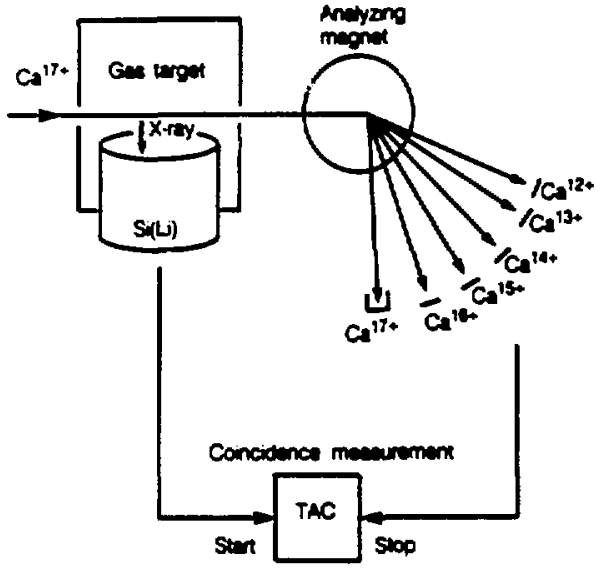

xaturese

FC. 1. Schemsic diagram of the apparatus, shown for $\mathrm{Ca}^{17+}$ projectile; eight particle detectors more und (only five are shown). Each particle detector goes to a separate time-to-amplitude convetue (TAC). The Si(Li) detactor is used to detect $x$-rays.

\section{CLOSE COLLISIONS OF $47-\mathrm{MeV} \mathrm{Ca}^{17+} \mathrm{NN}$ Ax}

A 47-MeV Ca ion has a velocity $\left(1.5 \times 10^{9} \mathrm{~cm} / \mathrm{s}\right)$ which is close to the velocity of the L-shell electrons of the Ar target $\left(1.0 \times 10^{9} \mathrm{~cm} / \mathrm{s}\right)$, and is slower than the K-shell electrons ${ }^{15}$ of the projectile $\left(4.2 \times 10^{9}\right.$ $\mathrm{cm} / \mathrm{s})$ and target $\left(3.4 \times 10^{9} \mathrm{~cm} / \mathrm{s}\right)$. K-vacancy production in either partner is therefore expected to be appropr ste's Ar'scribed in the molecular-orbital picture. . $\because$ amilu $M O$ diagram for the relevant states ? ' ine C. + this istem is shown in Fig. 2. An Ar $K$ elect. $n$ can bis imilsferred to the $L$ shell of the $\mathrm{Ca}^{17+}$ ion at an internuclear separation of about the K-sheil radius (approximately $0.08 \mathbf{n}_{0}$ ) via $2 \mathrm{po-2p \pi}$ rotational coupling. 16 The resulting vacancy in the A $\mathrm{K}$ shell can be shared with the outgoing $\mathrm{Ca}$ ion by subsequent 2po-1so radial coupling 17 at $A$ distance of several times the K-shell radius, giving rise to a $\mathrm{Ca}$ $K$ vacancy. Simultaneous with the $K-K$ transfer is the transfer of target L-and M-shell electrons to the projectile L shell, which has a high probability of occurtence over a range of several times the L-shell radius (see Fig. 2).

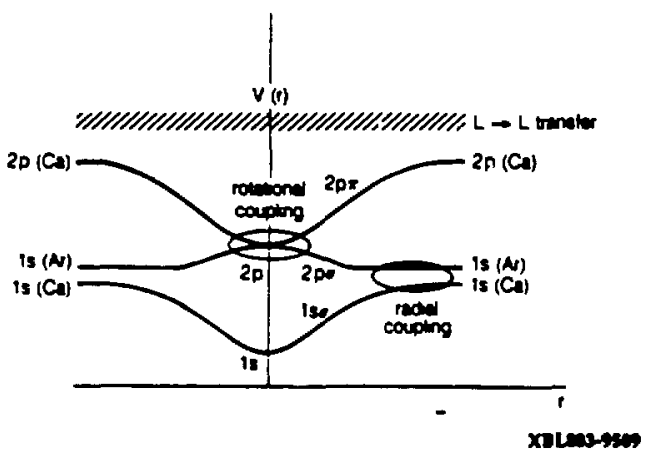

FC. 2. Schematic molecular-orbital diagram for the $\mathrm{Ca}+\mathrm{Ar}$ systen showing the relevant levels. Rotational coupling create an Ar K vacancy at small intemuclear separations; radial coupling (vacancy sharing) at hrget internuclear separations an lend to a Ca $K$ vecancy. L-L transfer occurs over a still larger range of internuclear separations (indicated schematically by the crose hatching).

Cross sections for $L$ - and $M$-shell electron capture coincident with a Ca K or Ar K X-ray are 
shown in Fig. 3 for 47-MeV Ca ${ }^{17+}$ in Ar. The cross sections for coincidence with an $A r K$ and $C a K x$-ray have pssentially the same shape, and in fact, coincide, if the cross sections for coincidence with an Ar $K x$-ray are shifted one charge state lower, as shown in Fig. 3. This shift is needed because an $\mathrm{Ar} K$ vacancy (Ar $\mathrm{K} \times$-ray emission) resulting from transfer of an Ar K electron to the $C_{a} L$ shell appears as a capture event by the $\mathrm{Ca}$ ion (Fig. 4a). For the case of emission of a C K x-ray, however, an electron has been returned to the Ar by K-vacancy sharing (Fig. $4 b)$, nesulting in no net change of charge for the $C a$ ion. The cross sections are thus compared in terms of capture of target L-and M-shell electrons only.

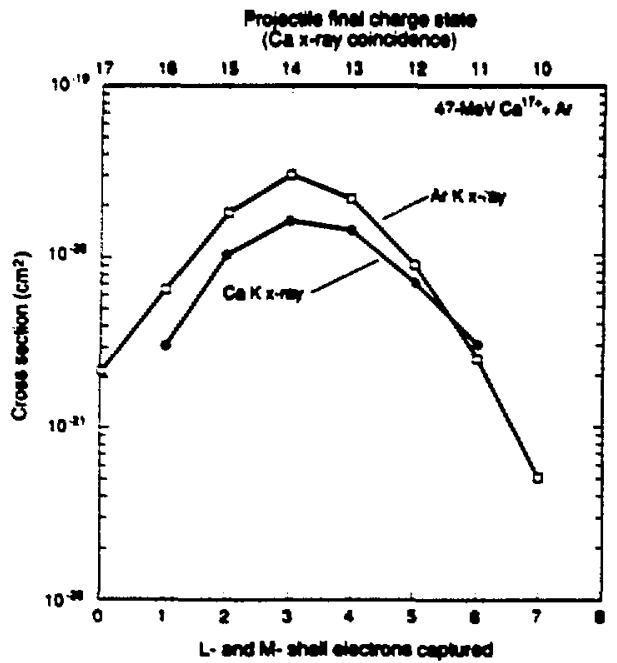

xuman

EIG. 3. Crow sections for electron capture in coincidence with an Ar or Ca KX-ay for 47 $\mathrm{MeV} \mathrm{Ca}^{17+}$ in As, as a function of the number of L-and M-shell electrons captured. The upper scale shows the projectile final charge state for coincidence with a $\mathrm{C}$ Kx-ray. The Ar $K x$ ray coincidence data have been shifted one charge state to the left to account for the promotion of an Ar K elactron to the Ca L-shell for the case of emistion of an Ar K X ray (soe (ext). (a)

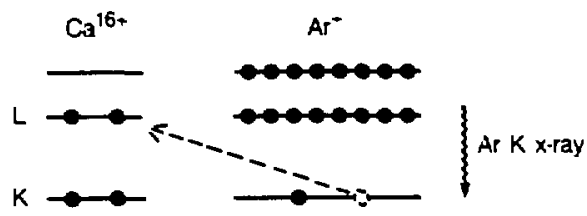

(b)

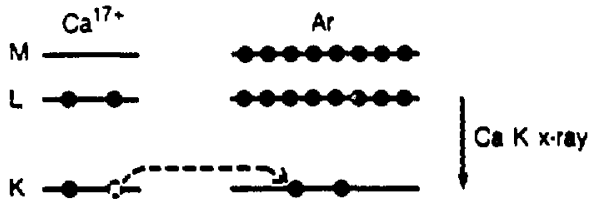

Xut wist

FC. 4. Schematic diagram of energy levels for $C^{17+}+A r$, showing (a) electron promotion and (b) vacancy sharing.

The electron-capture charge-state distribution can be described 18 by a binomial distribution if we ascume that the L-and M-shell electrons are captured due to electron-nucleus interactions and that electron-lectron interactions can be neglected, i.e., the electrons are captured without correlation. The binomial distribution for capture of $n$ electrons with a probability $P$ is written:

$$
P_{n}=()_{n}^{n}(1-p)^{y-n}
$$

where $t$ is the number of places into which electrons may be captured and ( ${ }_{n}$ ) is the binomial coefficient. The measured relative probability distributions for electron capture in coincidence with an Ar K x-ray (shifled one charge state lower) and with a Ca $K x$ ray are shown in Fig. 5, along with a binomial distribution which has been fit to the experimental data for $t=7$, giving an electron-capture probability $P$ $=0.45$ for the $A r K x$-ray data and $p=0.49$ for the $C$ $K x$-ray data. The good agreement of the measured change-state distribution with a binomial distribution is consistent with independent electroncopture events, and argues against significant ejectron correlation effects. 

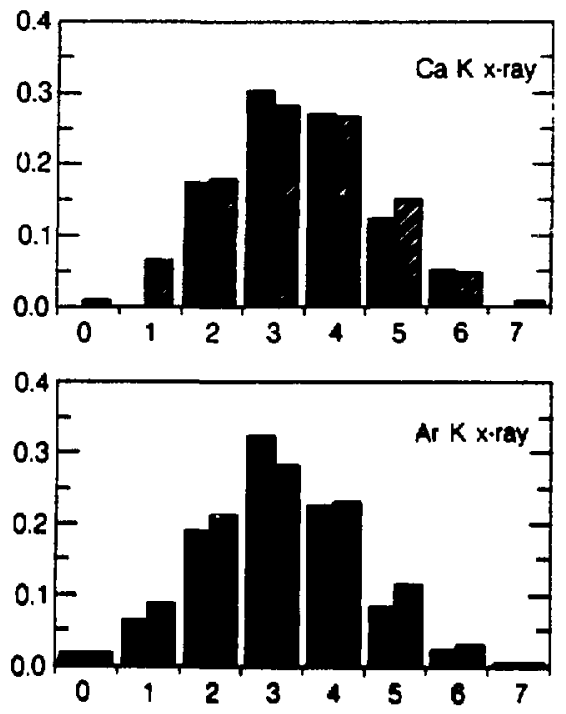

L. and M.enew enctrons ceptured

nat manes

FIC. 5. Relative electron-capture probabilitiea for 47-MaV $\mathrm{Ca}^{17+}$ in $\mathrm{Ar}$ as a function of the number of $L$ - and $M-$ ahell electrons transferned for coincidence with a $C$ a $K$ or Ar $K X$ ray. The distribution for coincidence with an Ar KX-ray has been shifted to the laft by one charge state (see text). Solid bars show the experimental results; sheded bers show the binomial distribution for an electron-capture probubility of 0.47 (awuming 7 electrons can be captured). The experimental probabilitios have ben normalized by a fector determind by the fit to the binomial distribution.

Experimental K-vacancy-sharing probabilities, wexp can be calculaled from the observed cross sections for electron capture in coincidence with a $C$ or Ar K x ray, corrected by neutral-atom fluorescence yields. Agreement of experimental values, wexp. with the theoretical 17 value $w$ th $=0.30$ is good for capture of up to four electrons, where neutral-aton $K$ binding energies have been used. The values of $w \exp$ for a larger range of number of electrons captured shows that $w$ exp increases with increasing number of electrons captured (Fig. 6). Possible explanations for this dependence are that the K-vacancy-production process is not truly independent of the electroncapture mechanism for collisions in which many electrons are captured, or that the use of neutral-atom fluorescence yields is inadequate.

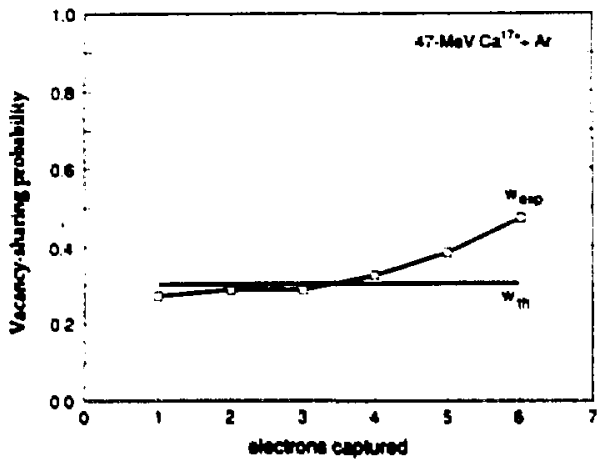

1C. 6. K vecancy thating probabilition an a functon of the number of $L$ - and M-shell electrons captured.

Experimemal probabilities, wexp are cakulated from the experimental results; $w_{\text {th }}$ is the theoretical value. 17

\section{CLOSE COLLISIONS OF 4 -MeV Ca IONS IN Ar: VARYING THE NUMBER OF VACANCIES IN THE CA L SHELL}

Cose collision of 47-MeV Ca ions in Ar have been further investigaved by varying the number of initial vacancies in the $L$ shell of the $C_{a-i o n}$ ions in charge states 10, 13, 15, 16, and 17 were used. Results are shown in Fig. 7, as a function of the number of $L$. shell electrons captured. Note that the absissas are offset to emphasize that the cross-section distributions have the same shape. This suggests that crow sections for electron loss in coincidence with - Ca or Ar K X-ray might be appreciable. 


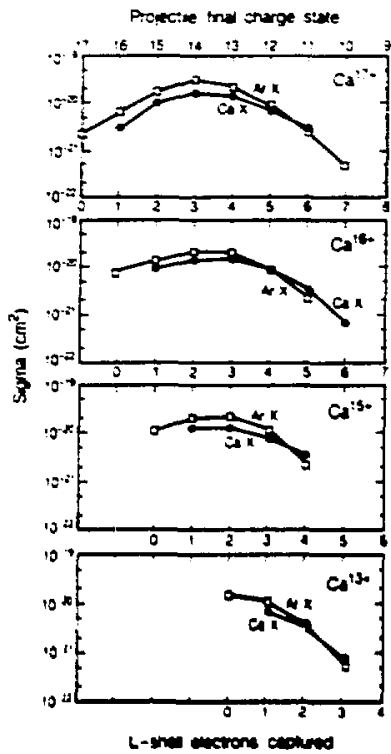

Xecenrim

FC. 7. Crow sections for electron eapture in coincidence with an Ar or Ca KX-ray for $47+M e V C a+$ in $A x$, for $q=13$, 15, 16 and 17, as a function of the numbe of L-thell eiectrons captured. The uppere scale show the projectile find charge stale for coincidence with a $C_{2} K x+r a y$. The Ar $K x$-ray coincidence data have bea shifted one chers? state to the laft.

The cross sections shown in Fis. $7 \mathrm{can}$ be fit with a binomial distribution, as has been done in Fig. 5 for Ca17+ ions. The result in each case is an electroncapture probability. These electron-capture probabilities are shown in Fig. 8 as a function of the number of initial vacancies in the $L$ shell of the $\mathrm{C}$ ion projectile. This electron-capture probubility is seen to be linear with the numbet of Ca-ion L-shell vacancies.

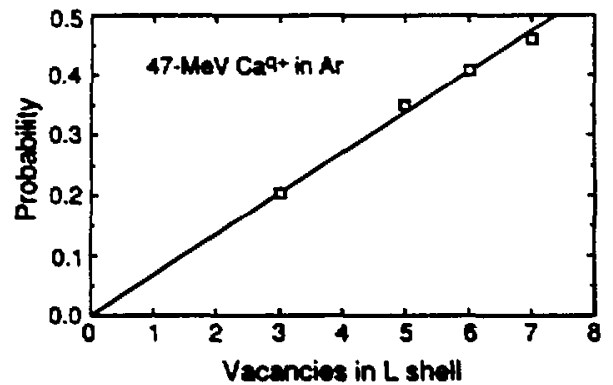

Xentrongen

FG. 8. Eectron-capture probubility as a function of the menber of vacancies in the $\mathrm{Ca} L$ thell for cloce collisions of 4-MeV Caq in Ar $(q-13,15,16$, and 17$)$.

\section{TOTAL EECTION CATTURE: 47-MEV CA KONS IN A}

Total electron-capture cross sections for 47-MeV C.17it in Ar are shown in Fig. 9. A total croses section for copture of up to eight electron in a single collision is observed. These cross sections, unlike those for close collisions (coincidence with a Ca or Ar K x-ray), which are aleo shown in Fig. 9, are a monotonically decreaning function of the number of electrons captured. We nove that close collisions are only a sinall fraction of the total number of collisions. although this fraction is found to increase with increasing number of electrons captured, a result which might arise from greater inierpenetration of the projactile and anget $\mathrm{L}$ shells for collisions in which a greater number of electrons are captured. 


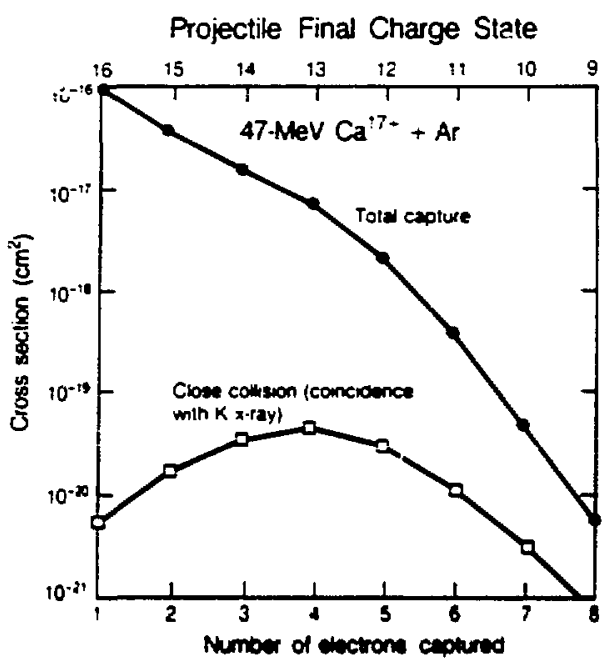

FC. 9. Total and $x$-ray coincident (um of As and Ca $K x-$ rays) electron-capture cross sections for $C^{17+}$ in Ar at 4 function of the number of electrons captured.

\section{ACNNOWLDCMENTS}

This work was supported by the Director, Office of Energy Research, Office of Fusion Energy, of the U.S. Department of Energy under Contract No. DE-ACOB76SF000ss, the U.S. Department of Energy, Office of Basic Energy Sciences, Division of Chemical Sciences, the Office of Health and Environmental Research under Contract No. DE-ACO6-76RLO1830, the Westem Michigan University Faculty Research and Creative Activities Support Fund, and the UKSERC.

\section{RERERENCES}

1. B. Rowner and D. Gur, Phys. Reo. A 15, 70 (1977).

2. E. N. Fuls, P. R. Jones, F. P. Ziemba, E. Everhart, Phys. Reo. 102704 (1957).

3. E. Everhart and Q. C. Keacel, Phys. Reo. 146,16 (1966).

4. V. V. Afrocimov, Yu S. Gondeev, M. Panov, and N. V. Fedorenko, Zh. Ekap. Teor. Fiz Piamn Red. 2.291 (1965); JETP Lett. 2185.

5. Q. C. Kesaed, Phys. Reo. A 2. 1881 (1970).

6. T. J. Gray, C. L. Cocke, and E. Justiniano, Phys. Rev. A 22. 849 (1960).
7. S. Kelbch, H. Schmidt-Böcking, J. Ulirich, R. Schuch, E. Justiniano, H. Ingwersen, and C. L. Cocke, Z. Phys. A 317,9 (1984).

8. S. Kelbch, J. Ullrich, R. Mann, P. Richard, and H. Schmidt-Böcking, J. Phys. B 18,323 (1985).

9. A. Müllex, B. Schuch, W. Groh, E. Salzborn, H. F. Beyer, P. H. Mokler, and R. E. Olson, Phys. Reo. A 33, 3010 (1986).

10. H. J. Swin, H. O. Lutz, P. H. Mokler, K. Sistemich, and P. Armbruster, Phys. Reo. Lett. 24. 701 (1970).

11. A. S. Schlachter, E. M. Bernstein, M. W. Clark, R. D. DuBois, W. G. Graham, R. H. McFarland, T. J. Morgan, D. W. Mueller, K. R. Stalder, J. W. Stearns, M. P. Stockli, and J. A. Tanis, I. Phys. B 21. L291 (1988).

12. S. Andriamonje, J. F. Chemin, J. Roturicr, B. Saboya, J. N. Scheurer, R. Gayet, A. Salin, H. Laurent, P. Asuer, and J. P. Thibaud, Z. Phys. A 312251 (1994).

13. A. S. Schlachter, J. W. Stearns, K. H. Bcrkner, E. M. Dembetin, M. W. Clark, R. D. DuBois, W. G. Graham, T. J. Morgan, D. W. Mueller, M. P. StockH, J. A. Tanis, and W. T. Woodland, Nucl. Instrum. Methods B 10/41, 21 (1989).

14. J. A. Tanis, E. M. Bernstein, M. P. Stockli, W. G. Graham, K. H. Berkner, D. J. Markevich, R. H. McFarland, R. V. Pyle, J. W. Stearns, and J. E. Willis, Phys. Reo. A 292232 (1984).

15 T. A. Cartion, C. W. Nestor, Jr., N. Waserman, and ]. D. McDowell, Atomic Data 2,63 (1970).

16. K. Taubjerg, J. S. Brigss, and J. Vaaban, J. Phys. B 21351 (1976).

17 W. E. Meyerhot, Pinys. Reo. Lett. 31 1341 (1973).

18. R. L. Kauffman, J. H. McGuire, P. Richard, and C. F. Moore, Phys. Reo. A \& 1233 (1973). 